\title{
Características do pasto e desempenho de novilhas em sistema silvipastoril e pastagem de braquiária em monocultivo
}

\author{
Domingos Sávio Campos Paciullo(1), Fernando César Ferraz Lopes(1), João Darós Malaquias Junior(2), \\ Antônio Viana Filho(2), Norberto Mario Rodriguez ${ }^{(3)}$, Mirton José Frota Morenz ${ }^{(4)}$ e Luiz Januário Magalhães Aroeira ${ }^{(1)}$ \\ (1)Embrapa Gado de Leite, Rua Eugênio do Nascimento, № 610, Dom Bosco, CEP 36038-330 Juiz de Fora, MG. E-mail: domingos@cnpgl.embrapa.br, \\ fernando@cnpgl.embrapa.br, ljmaroeira@yahoo.com.br (2)Universidade Católica de Goiás, Centro Técnico-Científico, Zootecnia, Avenida \\ Bela Vista, Km 02, s/no, Jardim Olímpico, CEP 74000-000 Goiânia, GO. E-mail: jdarosjr@uol.com.br (3)Universidade Federal de Minas \\ Gerais, Avenida Antônio Carlos, no 6.627, Caixa Postal 567, Campus da UFMG, CEP 30123-970 Belo Horizonte, MG. E-mail: norberto@vet.ufmg.br \\ (4)Universidade Federal Rural do Rio de Janeiro, BR 465, Km 7, CEP 23890-000 Seropédica, RJ. E-mail: mirtonmorenz@yahoo.com.br
}

Resumo - O objetivo deste trabalho foi avaliar as características do pasto e o desempenho de novilhas oriundas do cruzamento Holandês x Zebu, em sistema silvipastoril (SSP) e em monocultivo de braquiária (Urochloa decumbens). O delineamento experimental foi o de blocos ao acaso, com dois tratamentos: em monocultivo de braquiária; e o SSP, que apresentava faixas de braquiária consorciada com Stylosanthes guianensis, alternadas com faixas arborizadas. Os piquetes foram manejados sob lotação rotacionada, com 7 dias de ocupação e 35 e 49 dias de descanso, nas épocas chuvosa e seca, respectivamente. As características do pasto, o consumo e o ganho de peso não variaram com o sistema; porém, devido às reduções na quantidade e no valor nutritivo da forragem, apresentaram valores maiores na época chuvosa do que na época seca, respectivamente: massa de forragem pré-pastejo, 1.525 e $964 \mathrm{~kg} \mathrm{ha}^{-1}$; teores de proteína bruta na gramínea, 9,3 e 8,2\%; digestibilidade in vitro da matéria seca, 56,1 e 50,3\%; consumo de matéria seca, 2,3 e 1,6\% do peso vivo; ganho de peso de 625 e $242 \mathrm{~g}$ por dia por novilha. O sombreamento moderado no SSP não interferiu nas características do pasto, nem no consumo de forragem, nem no desempenho de novilhas leiteiras, quando comparado aos valores obtidos na pastagem de braquiária em monocultivo.

Termos para indexação: Urochloa decumbens, fibra em detergente neutro, massa de forragem, n-alcanos, proteína bruta, sombreamento.

\section{Pasture traits and heifer performance in a silvopastoral system and in an exclusive Brachiaria pasture}

\begin{abstract}
The objective of this work was to evaluate the pasture characteristics and the performance of heifers from the Holstein x Zebu cross in a silvopastoral system (SPS), and in a Brachiaria (Urochloa decumbens) pasture. The experiment was set up in a randomized block design with two treatments: an exclusive Brachiaria pasture; and SPS, which had mixed U. decumbens and Stylosanthes guianensis strips alternating with strips with trees. Paddocks were grazed in rotational stocking, with seven days of grazing and 35 and 49 days of rest in the rainy and dry seasons, respectively. Pasture traits, dry matter intake and live weight gain did not vary with the systems. However, due to the reduction in the amount and nutritional value of the forage, these variables had higher values for the rainy season than the dry season, respectively: pre-grazing forage mass, 1,525 and $964 \mathrm{~kg} \mathrm{ha}^{-1}$; crude protein, 9.3 and $8.2 \%$; in vitro dry matter digestibility, 56.1 and $50.3 \%$; dry matter intake, 2.3 and $1.6 \%$ of body weight; and live weight gain, 625 and $242 \mathrm{~g}$ per day per heifer. Moderate shading in SPS did not affect pasture traits, dry matter intake, or the performance of the heifers, in comparison to the values obtained for an exclusive Brachiaria pasture.
\end{abstract}

Index terms: Urochloa decumbens, neutral detergent fiber, forage mass, n-alkanes, crude protein, shading.

\section{Introdução}

Em diversas regiões do Brasil predominam sistemas de produção de bovinos leiteiros, com base na utilização de pastagens de braquiária que se degradam paulatinamente, por causa de manejo incorreto, caracterizado pela falta de adubação de manutenção, e excesso de animais na pastagem que resulta em superpastejo, entre outros fatores (Boddey et al., 2004). Associados a isso estão os baixos ganhos de peso 
vivo de novilhas leiteiras mantidas nessas pastagens, o que resulta em elevada idade ao primeiro parto e em redução dos índices de eficiência zootécnica e econômica dos sistemas de produção de leite. Atribuise esse desempenho inferior à escassez e ao baixo valor nutritivo do pasto, o que tem como consequência o reduzido consumo de matéria seca pelos animais.

Uma opção para superar esses problemas é a integração de pastagens com espécies arbóreas em sistemas silvipastoris (Rozados-Lorenzo et al., 2007; Paciullo et al., 2008). O uso de sistemas silvipastoris (SSP) apresenta efeitos benéficos, tais como a incorporação de nutrientes e o incremento da atividade microbiana do solo (Xavier et al., 2003; Neves et al., 2009), a melhoria do conforto térmico para os animais (Paes Leme et al., 2005) e a possibilidade de aumento do valor nutritivo da forragem (Paciullo et al., 2007; Sousa et al., 2007; Soares et al., 2009). A literatura indica que o crescimento das forrageiras depende de sua tolerância ao sombreamento e da percentagem de sombra imposta ao subbosque. Para gramíneas do gênero Urochloa sob sombreamento moderado - redução de 25 a $35 \%$ da radiação fotossinteticamente ativa - têm-se obtido produções de forragem semelhantes ou maiores do que a pleno sol (Paciullo et al., 2007; Guenni et al., 2008; Soares et al., 2009).

As melhorias nutricionais do pasto em sistemas silvipastoris resultantes do sombreamento e da maior disponibilidade de nutrientes no solo, associadas às melhores condições de conforto térmico dos animais, sinalizam a possibilidade de aumento no consumo de forragem e no ganho de peso de animais em pastejo. No entanto, são raros os trabalhos relacionados ao componente animal, nas condições de sistema silvipastoril. Reconhece-se que as informações sobre o consumo de animais em regime de pastejo são importantes para recomendações mais eficientes no plano nutricional, em relação à resposta animal e produtividade por área (Lopes et al., 2004; Aroeira et al., 2005; Paciullo et al., 2008).

O objetivo deste trabalho foi avaliar a massa de forragem, a capacidade de suporte, o valor nutritivo da forragem, o consumo voluntário de matéria seca e o desempenho de novilhas oriundas do cruzamento Holandês x Zebu, mantidas em sistema silvipastoril ou em pastagem de capim-braquiária em monocultivo, nas épocas seca e chuvosa do ano.

\section{Material e Métodos}

O trabalho foi realizado no Campo Experimental de Coronel Pacheco (CECP), da Embrapa Gado de Leite, Município de Coronel Pacheco, MG, $21^{\circ} 33^{\prime} 22^{\prime \prime S}, 43^{\circ} 6^{\prime} 15^{\prime \prime} \mathrm{W}$, e $410 \mathrm{~m}$ de altitude, de abril de 2003 a março de 2004. O clima da região, conforme Köppen, é do tipo Cwa (mesotérmico). O solo da área experimental é do tipo Latossolo Vermelho-Amarelo distrófico, de textura argilosa e relevo ondulado. Os atributos químicos do solo, no sistema silvipastoril e no monocultivo, eram, respectivamente: $\mathrm{pH}$ em água, 4,70 e 4,61; P disponível (Mehlich-1), 3,90 e 4,97 $\mathrm{mg} \mathrm{dm}^{-3}$; $\mathrm{Al}, 0,80 \mathrm{e} 0,73 \mathrm{cmol}_{\mathrm{c}} \mathrm{dm}^{-3} ; \mathrm{K}, 0,11$ e $0,11 \mathrm{cmol}_{\mathrm{c}} \mathrm{dm}^{-3} ; \mathrm{Ca}, 0,60$ e $0,30 \mathrm{cmol}_{\mathrm{c}} \mathrm{dm}^{-3}$; e $\mathrm{Mg}, 0,25$ e $0,12 \mathrm{cmol}_{\mathrm{c}} \mathrm{dm}^{-3}$. Os dados sobre a precipitação pluvial e a temperatura máxima e mínima foram coletados na Estação Meteorológica do CECP, distante, aproximadamente, $500 \mathrm{~m}$ da área experimental (Figura 1).

As avaliações foram realizadas em pastagem arborizada (sistema silvipastoril - SSP) e em pastagem de Urochloa decumbens em monocultivo, que constituíram os tratamentos experimentais. $\mathrm{O}$ delineamento experimental foi o de blocos ao acaso, com duas repetições. Ambas as pastagens foram estabelecidas em novembro de 1997, em área de 16 ha de topografia montanhosa com, aproximadamente, $30 \%$ de declividade.

$\mathrm{Na}$ implantação, o SSP foi constituído pela gramínea $U$. decumbens $\mathrm{cv}$. Basilisk, pela leguminosa herbácea Stylosanthes guianensis cv. Mineirão e pelas leguminosas arbóreas Acacia mangium, A. angustissima

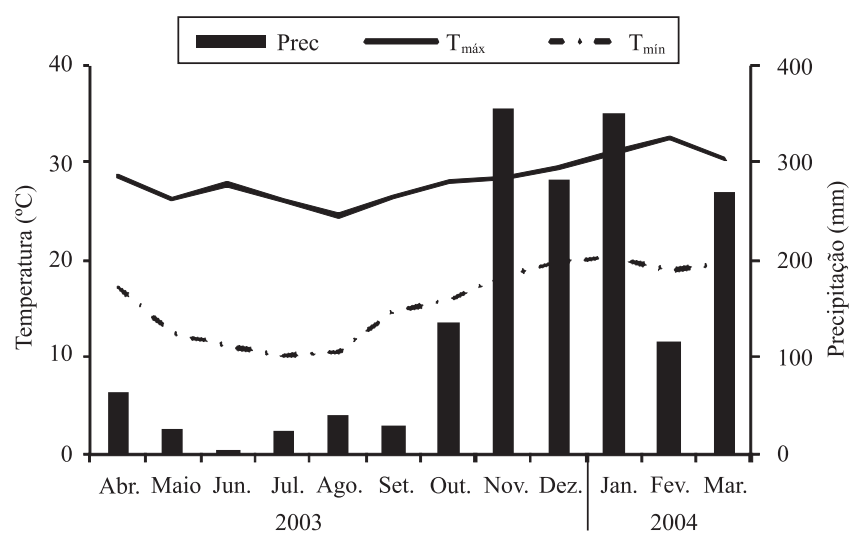

Figura 1. Médias mensais de temperaturas máxima $\left(\mathrm{T}_{\text {máx }}\right)$ e mínima $\left(\mathrm{T}_{\min }\right)$, e de precipitação pluviométrica (Prec) mensal acumulada, durante o período experimental. 
e Mimosa artemisiana, além de Eucalyptus grandis. As árvores foram distribuídas em faixas, cada uma com quatro linhas, no espaçamento $3 \times 3 \mathrm{~m}$. As faixas com árvores foram estabelecidas em nível no terreno, a cada $30 \mathrm{~m}$ de distância na área. A pastagem de braquiária estava estabelecida tanto na área sem árvores - $30 \mathrm{~m}$ entre as faixas com árvores - quanto sob as copas das árvores nas faixas.

Antes do plantio das espécies arbóreas, em novembro de 1997, aplicaram-se, de acordo com análise de solo, $1.000 \mathrm{~kg} \mathrm{ha}^{-1}$ de calcário dolomítico, $600 \mathrm{~kg} \mathrm{ha}^{-1} \mathrm{de}$ fosfato natural de Araxá, $250 \mathrm{~kg} \mathrm{ha}^{-1}$ de superfosfato simples, $100 \mathrm{~kg} \mathrm{ha}^{-1}$ de cloreto de potássio e $30 \mathrm{~kg} \mathrm{ha}^{-1}$ de micronutrientes (FTE BR-16). Para implantação da pastagem exclusiva de braquiária, seguiu-se o protocolo de preparo de solo e aplicação de corretivos e fertilizantes semelhante ao adotado dentro do SSP, uma vez que as áreas destinadas ao SSP e à pastagem de braquiária exclusiva eram contíguas e apresentavam a mesma declividade e tipo de solo. Depois do plantio, as áreas com pastagens não receberam aplicações adicionais de fertilizantes ou corretivos.

Medições da radiação fotossinteticamente ativa (RFA) foram realizadas com auxílio de um sensor de RFA (modelo LI-190SA) conectado a um radiômetro portátil (LI-COR, modelo LI-189). Constatou-se que no SSP havia sombreamento médio de $26 \%$ da RFA plena (18 a 35\%), considerando-se as faixas com e sem árvores.

Entre 1998 e 2000, a pastagem arborizada permaneceu vedada, para garantir o crescimento inicial das espécies arbóreas. As pastagens foram divididas em 32 piquetes de 0,5 ha, sendo 16 ha para cada tratamento (SSP e pastagem de braquiária). Foram instaladas duas repetições de área por tratamento, cada um constituído pelo conjunto de oito piquetes. Entre 2001 e 2003, as pastagens foram utilizadas para o pastejo de vacas não lactantes, conforme manejo descrito por Aroeira et al. (2005).

Cada grupo de piquetes, de cada repetição de área, foi pastejado por quatro novilhas $1 / 2,3 / 4$ e $7 / 8$ Holandês $\mathrm{x}$ Zebu (animais de prova), de peso vivo inicial médio de $250 \mathrm{~kg}$. As novilhas foram dispostas em blocos conforme o peso vivo e a composição genética. Para assegurar oferta de forragem de aproximadamente $7,5 \mathrm{~kg}$ de MS - com base na massa seca da forragem verde - para cada $100 \mathrm{~kg}$ de peso vivo, ao longo do tempo, animais reguladores foram colocados $\mathrm{e}$ retirados de cada piquete, de acordo com a necessidade. Os piquetes foram manejados segundo o método de lotação rotacionada, com sete dias de ocupação e 35 e 49 dias de descanso, durante as estações das chuvas e seca, respectivamente. No período seco, os oito piquetes foram usados para o pastejo dos animais de prova; na época das chuvas, apenas seis dos oito piquetes foram usados para o experimento, e os outros dois foram manejados com animais reguladores.

As avaliações de massa de forragem foram realizadas imediatamente antes da entrada dos animais no piquete (pré-pastejo), a cada 14 dias, em piquetes alternados. Em cada piquete foram coletadas vinte amostras de $0,25 \mathrm{~m}^{2}$, separadas manualmente em capim-braquiária, estilosantes Mineirão e material morto. Cada componente foi pesado e levado à estufa para pré-secagem a $55^{\circ} \mathrm{C}$, para determinar o teor de matéria pré-secada.

As amostras de forragem verde seca da gramínea, coletadas em maio, julho, setembro, outubro, dezembro e março, foram analisadas para determinar os teores de proteína bruta $(\mathrm{PB})$, fibra em detergente neutro (FDN), fibra em detergente ácido (FDA) e lignina, além da digestibilidade in vitro da matéria seca (DIVMS), conforme protocolos descritos por Silva \& Queiroz (2002).

A estimativa do consumo de matéria seca de pasto (CMS) foi realizada em três ocasiões durante a época seca - maio, julho e setembro de 2003 - e três durante a época chuvosa - outubro e dezembro de 2003 e março de 2004. Foram utilizadas 12 das 16 novilhas disponíveis, ou seja, três de cada repetição de área de pastagem de cada tratamento. Utilizou-se a técnica dos n-alcanos, que foram administrados a cada novilha por meio de cápsula de liberação controlada (CRC, type MCM, Captec Ltd., Auckland, New Zealand), com os n-alcanos $\mathrm{C}_{32} \mathrm{H}_{66}$ e $\mathrm{C}_{36} \mathrm{H}_{74}$. A administração da cápsula foi realizada uma única vez, pela manhã, e os primeiros sete dias foram destinados à obtenção do estado de equilíbrio na excreção do indicador. As coletas diárias de fezes foram realizadas sempre pela manhã, durante sete dias, a partir do oitavo dia da administração da cápsula. $\mathrm{O}$ procedimento de coleta de fezes baseouse no acompanhamento de cada novilha na pastagem, até que ocorresse defecação espontânea. As amostras coletadas foram pré-secadas $\left(72 \mathrm{~h}, 55^{\circ} \mathrm{C}\right)$, moídas $(1 \mathrm{~mm})$, agrupadas por novilha x período, e analisadas quanto ao perfil de n-alcanos. Nas amostras de forragem, 
obtidas por meio de pastejo simulado, e nas de fezes, foram determinadas as concentrações dos n-alcanos $\mathrm{C}_{27} \mathrm{H}_{56}$ a C$_{35} \mathrm{H}_{72}$, por meio de cromatografia gasosa, com o $\mathrm{C}_{34} \mathrm{H}_{70}$ como padrão interno. Para o cálculo do CMS de pasto, foi utilizada a equação apresentada por Mayes et al. (1986), e o par de n-alcanos $\mathrm{C}_{33} \mathrm{H}_{68}: \mathrm{C}_{32} \mathrm{H}_{66}$.

Para determinar a composição botânica da dieta no SSP, foi utilizado o programa "EatWhat", que prescinde dos valores dos perfis das concentrações de n-alcanos nas forrageiras e nas amostras individuais de fezes (Dove \& Moore, 1995). O consumo diferenciado de cada espécie forrageira foi obtido, então, a partir de suas proporções em relação ao CMS total.

A cada 35 dias, todos os animais foram pesados. O ganho diário de peso vivo dos animais foi usado para estimar o desempenho das novilhas. Também foi computado o número de dias em que os animais reguladores permaneceram na pastagem, para possibilitar as estimativas da capacidade de suporte dos pastos.

Os dados foram analisados separadamente por época do ano (seca e chuvosa). Para a análise de variância dos dados, foi utilizado o procedimento GLM (general linear models), (SAS Institute, 2001), com a opção de medidas repetidas no tempo, caracterizadas pelos períodos de avaliação em cada época do ano. Assim, para os dados de massa de forragem, foram usados seis períodos (meses) para cada época do ano: abril a setembro, para a época seca; e outubro a março, para a época chuvosa. Para os dados de valor nutritivo e consumo, foram analisados três períodos para cada época do ano: maio, julho e setembro, para a época seca; e outubro, dezembro e março, para a chuvosa. Para a taxa de lotação e o ganho de peso vivo por animal, foram usados os valores de cinco pesagens em cada época do ano. As médias foram comparadas pelo teste de Tukey, a 5\% de probabilidade.

\section{Resultados e Discussão}

A massa de matéria seca de forragem verde (MSFV) do pasto não foi influenciada $(p>0,05)$ pelo tipo de pastagem - SSP e pastagem de braquiária em monocultivo -, mas variou com o mês do ano (Figura 2). Em média, a MSFV pré-pastejo foi de 964, durante a época seca, e de $1.525 \mathrm{~kg} \mathrm{ha}^{-1}$, na época chuvosa. Observou-se redução da MSFV entre os meses de abril e setembro e aumento progressivo a partir de outubro, início da época chuvosa na região. Aflutuação da MSFV ao longo do ano caracteriza a forte estacionalidade na produção de forragem, conforme relatado por outros autores na mesma região (Lopes et al., 2004; Aroeira et al., 2005; Paciullo et al., 2008).

No SSP, a redução de luminosidade não interferiu na massa de forragem, o que pode ser atribuído à tolerância da braquiária ao sombreamento moderado (Paciullo et al., 2007; Guenni et al., 2008). Da mesma forma, a taxa de lotação não variou com o sistema de recria (1,6 novilha ha ${ }^{-1}$ na época seca, e 2,2 novilhas ha ${ }^{-1}$ na época chuvosa, correspondentes a 0,9 e 1,3 $\mathrm{UA} \mathrm{ha}^{-1}$, respectivamente, considerando-se a média dos dois sistemas), o que demonstra a semelhança na capacidade de suporte dos sistemas. O capim-braquiária apresenta ajustes morfofisiológicos, em resposta ao sombreamento, tais como aumentos da relação parte aérea/raiz, da área foliar específica e da taxa de alongamento foliar, o que lhe permite manutenção da produtividade, mesmo em condições de limitação luminosa (Guenni et al., 2008; Paciullo et al., 2008).

O estilosantes esteve presente na pastagem apenas nos meses da época seca (Figura 2). Os resultados de Aroeira et al. (2005) já indicavam início de redução da percentagem de estilosantes na mesma pastagem deste estudo, a partir de 2001. A baixa persistência de leguminosas consorciadas com gramíneas é frequentemente relatada na literatura (Aroeira et al.,

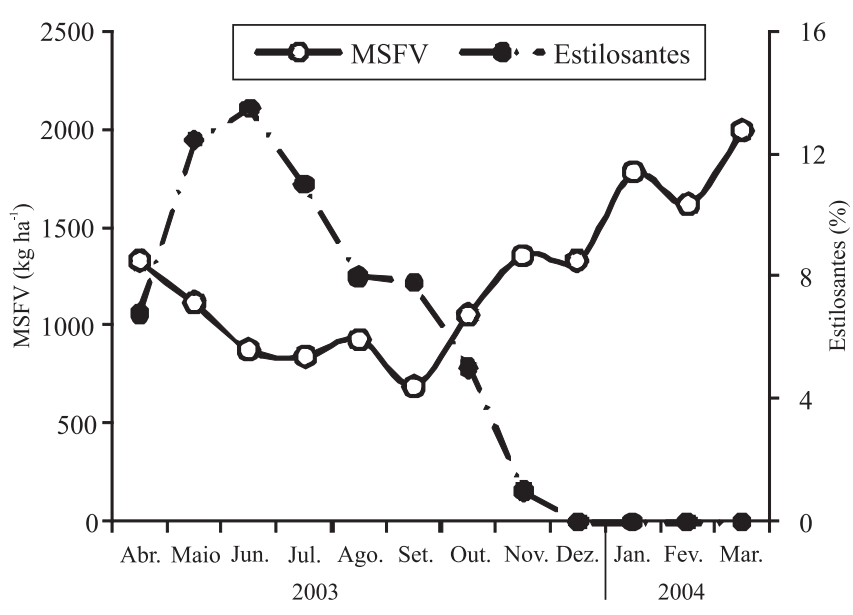

Figura 2. Massa de matéria seca de forragem verde (MSFV - valores médios do sistema silvipastoril e da pastagem de Urochloa decumbens em monocultivo) e percentagem de estilosantes na MSFV, no sistema silvipastoril, em razão do mês do ano. 
2005) e é atribuída a vários fatores. No caso do estilosantes Mineirão, sua baixa persistência pode ser atribuída à baixa capacidade de ressemeadura demonstraram que as plantas existentes completaram seu ciclo de vida até o final do período seco, não tendo ocorrido recrutamento do banco de sementes com o início do período chuvoso. Deve-se considerar, também, que a alta agressividade da $U$. decumbens pode ter contribuído para diminuir a percentagem de estilosantes na pastagem. Andrade et al. (2003) constataram que quanto maior a agressividade da gramínea, menor a persistência do estilosantes Mineirão no sub-bosque de um sistema silvipastoril.

Não foram observadas diferenças $(\mathrm{p}>0,05)$ na composição químico-bromatológica da forragem dois sistemas avaliados para nenhuma das épocas do ano. Esse resultado surpreende, considerando-se as melhorias do valor nutritivo de gramíneas expostas ao sombreamento (Paciullo et al., 2007; Souza et al., 2007; Soares et al., 2009). Para U. decumbens, Paciullo et al. (2007) verificaram teores de PB 29\% maiores sob sombreamento que a pleno sol, além de redução dos teores de FDN e aumento da DIVMS. Soares et al. (2009) relataram maiores teores de PB e menores de FDN da $U$. brizantha sombreada, em relação ao cultivo ao sol pleno. No entanto, a literatura também mostra efeitos inconsistentes da sombra nos teores de fibra e na digestibilidade de forrageiras. Dependendo da espécie, época do ano e percentagem de sombreamento, ocorre aumento, redução ou ausência de efeitos do sombreamento sobre os teores de FDN e lignina e sobre a DIVMS de forrageiras (Senanayake, 1995; Deinum et al., 1996). No presente trabalho, ressalta-se que a área da pastagem sob sombreamento mais intenso representava, aproximadamente $30 \%$ da área total do SSP, uma vez que as árvores estavam dispostas em faixas na pastagem. É possível que os efeitos benéficos das árvores sobre o valor nutritivo do capim-braquiária, que crescia no sub-bosque, tenham sido diluídos nos valores médios obtidos em todo o sistema, principalmente porque $70 \%$ das amostras foram coletadas na área de $30 \mathrm{~m}$ de capim-braquiária, entre as faixas de árvores. Tal fato contribuiu para a semelhança dos valores obtidos no SSP e na pastagem exclusiva de capim-braquiária. natural (Barcellos et al., 2001). Os resultados obtidos verde do capim-braquiária entre as pastagens dos

Todos os componentes nutricionais variaram $(\mathrm{p}<0,05)$ com o mês do ano, com exceção dos teores de lignina na época chuvosa (Tabela 1). Durante a época seca, o teor de PB foi menor em maio e julho, e maior em setembro, enquanto o de FDN foi maior em julho e menor em setembro; em maio, o valor foi intermediário aos obtidos nos outros dois meses. Os maiores teores de FDA e lignina foram observados em julho. A DIVMS foi maior em setembro e menor em julho, com valor intermediário e semelhante aos extremos em março. De forma geral, o melhor valor nutritivo do pasto em setembro, caracterizado por maiores valores de PB e DIVMS, e menores de FDN e FDA, coincidiu com o início da elevação da temperatura mínima média diária, que havia permanecido inferior a $15^{\circ} \mathrm{C}$ entre os meses de maio e agosto (Figura 1). A incidência de pequena quantidade de chuvas entre agosto e setembro, associada ao aumento da temperatura, propiciou o aparecimento de novas brotações, com melhor valor nutricional que nos demais meses da época seca.

A partir de outubro, durante a época chuvosa, houve redução no valor nutritivo da forragem, principalmente em função do avanço da maturidade das plantas. Os teores de FDN, FDA e lignina foram, de modo geral, crescentes e os de PB decrescentes $(p<0,05)$, tendência compatível com o decréscimo dos coeficientes de DIVMS (Tabela 1).

Os n-alcanos encontrados em maiores concentrações no capim-braquiária, independentemente da época do ano e do ambiente, foram o $\mathrm{C}_{31} \mathrm{H}_{64}$ e o $\mathrm{C}_{33} \mathrm{H}_{68}$ (Tabela 2),

Tabela 1. Valores médios da composição químico-bromatológica da forragem verde de Urochloa decumbens dos dois sistemas (silvipastoril e monocultivo $U$. decumbens), em razão do mês e da época do ano ${ }^{(1)}$.

\begin{tabular}{|c|c|c|c|c|}
\hline Característica & Maio/2003 & Jul./2003 & Set./2003 & $\mathrm{CV}(\%)$ \\
\hline & \multicolumn{4}{|c|}{ Época seca } \\
\hline PB (\% da MS) & $7,6 \mathrm{~b}$ & $6,2 \mathrm{~b}$ & $11,0 \mathrm{a}$ & 8,9 \\
\hline FDN (\% da MS) & $68,9 \mathrm{ab}$ & $71,5 \mathrm{a}$ & $66,5 b$ & 1,7 \\
\hline FDA ( $\%$ da MS $)$ & $32,4 a$ & $33,3 \mathrm{a}$ & $28,8 b$ & 2,6 \\
\hline Lignina (\% da MS) & $10,1 \mathrm{bc}$ & $12,6 \mathrm{a}$ & $10,9 b$ & 4,3 \\
\hline \multirow[t]{3}{*}{ DIVMS (\%) } & $49,4 \mathrm{ab}$ & $47,8 \mathrm{~b}$ & $53,8 \mathrm{a}$ & 5,0 \\
\hline & Out./2003 & Dez./2003 & Mar./2004 & \\
\hline & \multicolumn{4}{|c|}{ Época chuvosa } \\
\hline PB (\% da MS) & $10,3 a$ & $9,6 \mathrm{ab}$ & $8,0 \mathrm{~b}$ & 9,3 \\
\hline FDN ( $\%$ da MS $)$ & $61,8 \mathrm{a}$ & $69,5 b$ & $73,6 b$ & 3,6 \\
\hline FDA ( $\%$ da MS $)$ & $27,3 \mathrm{a}$ & $34,6 b$ & $34,8 b$ & 4,9 \\
\hline Lignina (\% da MS) & $8,5 \mathrm{a}$ & $8,4 a$ & $9,5 \mathrm{a}$ & 5,3 \\
\hline DIVMS (\%) & $61,0 \mathrm{a}$ & $57,0 \mathrm{ab}$ & $50,4 b$ & 9,5 \\
\hline
\end{tabular}

Pesq. agropec. bras., Brasília, v.44, n.11, p.1528-1535, nov. 2009 
o que corrobora os resultados de Delgado et al. (2000), onde as concentrações para os n-alcanos $\mathrm{C}_{31} \mathrm{H}_{64}$ e $\mathrm{C}_{33} \mathrm{H}_{68}$, em amostras de $U$. decumbens, variaram, respectivamente, de 121 a 164, e de 153 a $340 \mathrm{mg} \mathrm{kg}^{-1}$ de MS. Para estilosantes, foram encontrados em maiores concentrações os n-alcanos $\mathrm{C}_{31} \mathrm{H}_{64}, \mathrm{C}_{33} \mathrm{H}_{68}$ e $\mathrm{C}_{29} \mathrm{H}_{60}$ (Tabela 2). Ao trabalhar com feno de $S$. guianensis, Ali et al. (2005) relataram valores de 153, 198 e $36 \mathrm{mg} \mathrm{kg}^{-1}$ de MS para $\mathrm{C}_{31} \mathrm{H}_{64}, \mathrm{C}_{33} \mathrm{H}_{68}$ e $\mathrm{C}_{29} \mathrm{H}_{60}$, respectivamente.

$\mathrm{O}$ consumo de matéria seca não diferiu $(\mathrm{p}>0,05)$ entre os sistemas em relação a nenhuma época do ano (Tabela 3). Na época seca, o CMS diminuiu $(\mathrm{p}<0,05)$ com o avanço da estação, o que foi atribuído à redução da oferta de forragem. Embora tenha sido meta a manutenção de oferta de MSFV de aproximadamente $7,5 \%$ do $\mathrm{PV}$, isto não foi possível durante julho e agosto, devido à redução acentuada da massa de forragem. Assim, a oferta média durante a época seca foi de $5,2 \%$ do PV, o que provavelmente limitou o CMS das novilhas em pastejo. Em julho, além da baixa oferta de forragem, o baixo valor nutricional da forragem pode ter contribuído também para a redução do CMS. O teor de PB de 6,2\%, observado em julho (Tabela 1), está abaixo do teor proteico crítico de 7\% (Milford \& Minson, 1966), considerado como limitante para o CMS em ruminantes. Os elevados valores de CMS estimados em maio de 2003 foram considerados atípicos, já que nesse mês, houve início de redução na quantidade de forragem e na qualidade do pasto (Figura 2 e Tabela 1). Contudo, argumentase que, em maio, início do período seco do ano, ainda foi possível manter a oferta de forragem de $7 \%$ do PV, valor próximo da meta inicialmente proposta para o manejo das pastagens. Embora esse fato não justifique completamente o alto consumo estimado em maio, ajuda a explicar a diferença acentuada nos valores de consumo de maio em relação aos demais meses da época seca.

$\mathrm{Na}$ época seca, foi verificada a ingestão de estilosantes pelas novilhas nos meses de julho e setembro - 11 e $6 \%$ do consumo total de matéria seca, respectivamente -, a despeito da pequena participação da leguminosa na pastagem - entre 6 e $13 \%$ da MSFV. A contribuição do estilosantes Mineirão, para a nutrição de bovinos em pastejo, pode ser importante na época seca (Aroeira et al., 2005), quando a produção de forragem da gramínea decresce, devido às condições climáticas desfavoráveis. Durante o período seco, Galindo et al. (1999) observaram melhor desempenho de novilhos em pastagens de capim-braquiária, consorciadas com estilosantes Mineirão, do que com dieta exclusiva de gramíneas.

O CMS não variou durante a época chuvosa (Tabela 3). Nesse período, foi possível manter oferta média de 7,3\% do PV (7,5 e 7,1\% PV, respectivamente para o SSP e a pastagem de braquiária). Essa oferta de forragem é duas a três vezes superior aos valores esperados de CMS de animais em pastagens tropicais (Lopes et al., 2004; Morenz et al., 2006; Paciullo et al., 2008), e está dentro da faixa de oferta de forragem de 5 a $7,5 \mathrm{~kg} 100 \mathrm{~kg}^{-1}$ de peso vivo, sugerida por Gomide (1993), para evitar restrição no consumo voluntário de MS pelo animal em pastejo. Euclides et al. (2000) observaram consumo de MS de 2,6\% do PV por novilhos Nelore, em regime de pastejo em $U$. decumbens. Os valores de consumo de pasto durante a época chuvosa, observados no presente trabalho, estão condizentes com o valor de $2,4 \%$ de PV recomendados pelo National Research Council (2001) para novilhas em crescimento (raça pequena, peso à maturidade de $450 \mathrm{~kg}$ ).

$O$ ganho de peso vivo por animal não variou $(p>0,05)$ com o sistema de recria, nem com as datas de pesagem.

Tabela 2. Concentração de n-alcanos (mg kg-1 de matéria seca), em amostras de Urochloa decumbens (BRA) e Stylosantes guianensis, obtidas por meio de pastejo simulado, em sistema silvipastoril (SSP) e pastagem de $U$. decumbens em monocultivo (MONO) na época seca e chuvosa.

\begin{tabular}{|c|c|c|c|c|c|c|c|c|}
\hline Espécie & $\mathrm{C}_{27}$ & $\mathrm{C}_{28}$ & $\mathrm{C}_{29}$ & $\mathrm{C}_{30}$ & $\mathrm{C}_{31}$ & $\mathrm{C}_{32}$ & $\mathrm{C}_{33}$ & $\mathrm{C}_{35}$ \\
\hline & \multicolumn{8}{|c|}{ Época seca } \\
\hline BRA SSP & 16,6 & 10,3 & 48,3 & 13,5 & 173,3 & 16,8 & 243,1 & 69,8 \\
\hline BRA MONO & 17,2 & 11,2 & 44,4 & 14,2 & 167,7 & 16,7 & 235,5 & 70,7 \\
\hline S. guianensis & 20,0 & 19,5 & 210,6 & 29,8 & 530,3 & 32,3 & 199,6 & 4,9 \\
\hline & \multicolumn{8}{|c|}{ Época chuvosa } \\
\hline BRA SSP & 22,4 & 12,5 & 46,1 & 5,8 & 119,6 & 12,9 & 188,0 & 69,3 \\
\hline BRA MONO & 18,6 & 9,4 & 39,6 & 5,0 & 115,3 & 12,2 & 168,0 & 58,2 \\
\hline
\end{tabular}


Foram observados ganhos médios, considerando-se os dois sistemas, de 242 e $625 \mathrm{~g}$ por dia por novilha, para as épocas seca e chuvosa, respectivamente. Ganhos de peso vivo médio de $600 \mathrm{~g}$ por dia, como os observados neste trabalho, na época chuvosa, permitiriam desenvolvimento ponderal acelerado para novilhas leiteiras em crescimento, e garantiriam precocidade à primeira cobertura e ao primeiro parto. Porém, a escassez de forragem no período da seca reduz consideravelmente os ganhos de peso, o que exige estratégias de manejo e suplementação, quando se deseja manter médias elevadas de ganho de peso ao longo de todo o ano.

A semelhança nos valores de CMS e ganho de peso, obtidos nos dois sistemas, não condiz com a hipótese de que em pastejo no sistema silvipastoril, melhorias no valor nutricional do pasto e nas condições de conforto térmico dos animais, decorrentes do sombreamento, podem aumentar o CMS e melhorar o desempenho de novilhas. Embora existam fortes evidências de que a amenização da temperatura, em sistemas silvipastoris, interfere positivamente no comportamento de vacas mestiças Holandês x Zebu, com o aumento nos tempos de pastejo e ruminação, e com a redução da temperatura da superfície corporal e da sudorese (Paes Leme et al., 2005), tais mudanças, aparentemente, não foram suficientes para influenciar o desempenho das novilhas. $\mathrm{O}$ valor nutricional do pasto tampouco foi alterado significativamente pela sombra, em razão, provavelmente, da menor proporção de área de pasto sombreada, em relação à não sombreada, no sistema silvipastoril.

Tabela 3. Consumo de matéria seca (CMS) de novilhas Holandês x Zebu, em sistema silvipastoril (SSP) e pastagem de Urochloa decumbens em monocultivo (BRA), em razão do mês e da época do ano(1).

\begin{tabular}{|c|c|c|c|}
\hline \multirow[t]{2}{*}{ Mês/ano } & \multicolumn{2}{|c|}{ CMS (\% PV) } & \multirow[t]{2}{*}{ Média } \\
\hline & SSP & BRA & \\
\hline \multicolumn{4}{|c|}{ Época seca } \\
\hline Maio/2003 & 3,0 & 2,9 & $3,0 \mathrm{a}$ \\
\hline Jul./2003 & 1,7 & 1,7 & $1,7 b$ \\
\hline Set./2003 & 1,5 & 1,4 & $1,5 b$ \\
\hline Média & $2,1 \mathrm{~A}$ & $2,0 \mathrm{~A}$ & 2,1 \\
\hline \multicolumn{4}{|c|}{ Época chuvosa } \\
\hline Out./2003 & 2,3 & 2,1 & $2,2 \mathrm{a}$ \\
\hline Dez./2003 & 2,4 & 2,4 & $2,4 a$ \\
\hline Mar./2004 & 2,4 & 2,2 & $2,3 \mathrm{a}$ \\
\hline Média & $2,4 \mathrm{~A}$ & $2,2 \mathrm{~A}$ & 2,3 \\
\hline
\end{tabular}

\section{Conclusões}

1. O sombreamento moderado no sistema silvipastoril não interfere na capacidade de suporte do pasto, no valor nutritivo, no consumo de matéria seca e no desempenho de novilhas leiteiras, em comparação aos valores obtidos na pastagem de $U$. decumbens em mono cultivo a céu aberto.

2. Pastagens de braquiária, em sistema silvipastoril ou em monocultivo, possibilitam acelerado crescimento de novilhas mestiças leiteiras durante a época chuvosa, mas, na seca, o consumo de pasto e o ganho de peso são reduzidos em ambos os sistemas.

\section{Referências}

ALI, H.A.M.; MAYES, R.W.; HECTOR, B.L.; ORSKOV, E.R. Assessment of n-alkanes, long-chain fatty alcohols and long-chain fatty acids as diet composition markers: the concentrations of these compounds in rangeland species from Sudan. Animal Feed Science and Technology, v.121, p.257-271, 2005.

ANDRADE, C.M.S.; GARCIA, R.; COUTO, L.; PEREIRA, O.G.; SOUZA, A.L. Desempenho de seis gramíneas solteiras ou consorciadas com o Stylosanthes guianensis cv. Mineirão e Eucalipto em sistema silvipastoril. Revista Brasileira de Zootecnia, v.32, p.1845-1850, 2003.

AROEIRA, L.J.M.; PACIULLO, D.S.C.; LOPES, F.C.F.; MORENZ, M.J.F.; SALIBA, E.S.; SILVA, J.J. da; DUCATTI, C. Disponibilidade, composição bromatológica e consumo de matéria seca em pastagem consorciada de Brachiaria decumbens com Stylosanthes guianensis. Pesquisa Agropecuária Brasileira, v.40, p.413-418, 2005.

BARCELLOS, A. de O.; ANDRADE, R.P. de; KARIA, C.T.; VILELA, L. Potencial e uso de leguminosas forrageiras dos gêneros Stylosanthes, Arachis e Leucaena. In: SIMPÓSIO SOBRE MANEJO DA PASTAGEM, 17., 2001, Piracicaba. A planta forrageira no sistema de produção: anais. Piracicaba: FEALQ, 2001. p.365-425.

BODDEY, R.M.; MACEDO, R.; TARRÉ, R.M.; FERREIRA, E.; OLIVEIRA, O.C.; REZENDE, C.P.; CANTARUTTI, R.B.; PEREIRA, J.M.; ALVES, B.J.R.; URQUIAGA, S. Nitrogen cycling in Brachiaria pastures: the key to understanding the process of pasture decline. Agriculture Ecosystems and Environment, v.103, p.389-403, 2004.

DEINUM, B.; SULASTRI, R.D.; ZEINAB, M.H.J.; MAASSEN, A. Effects of light intensity on growth, anatomy and forage quality of two tropical grasses (Brachiaria brizantha and Panicum maximum var. trichoglume). Netherlands Journal of Agriculture Science, v.44, p.111-124, 1996.

DELGADO, D.C.; OLIVERA, M.C.; NAVARRO, A. Composition of cuticular n-alkanes in tropical plants. Their potential as markers to estimate consumption and selection of grazing ruminants. Cuban Journal of Agriculture Science, v.34, p.147-152, 2000. 
DOVE, H.; MOORE, A.D. Using a least-squares optimization procedure to estimate botanical composition based on the n-alkanes of plant cuticular wax. Australian Journal of Agriculture Research, v.46, p.1535-1544, 1995.

EUCLIDES, V.P.B.; CARDOSO, E.G.; MACEDO, M.C.M.; OLIVEIRA, M.P. Consumo voluntário de Brachiaria decumbens cv. Basilisk e Brachiaria brizantha cv. Marandu sob pastejo. Revista Brasileira de Zootecnia, v.29, p.2200-2208, 2000.

GALINDO, L.G.; AYARZA, M.; ALVES, B.J.R.; URQUIAGA, S.; OLIVEIRA, O.C.; BODDEY, R.M. Produção animal em pastagem consorciada de Stylosanthes guianensis e Brachiaria ruziziensis na Região dos Cerrados. In: REUNIÃO ANUAL DA SOCIEDADE BRASILEIRA DE ZOOTECNIA, 36., 1999, Porto Alegre. Anais. Porto Alegre: Sociedade Brazileira de Zootecnia, 1999. 1 CD ROM.

GOMIDE, J.A. Produção de leite em regime de pasto. Revista Brasileira de Zootecnia, v.22, p.591-613, 1993.

GUENNI, O.; SEITER, S.; FIGUEROA, R. Growth responses of three Brachiaria species to light intensity and nitrogen supply. Tropical Grasslands, v.42, p.75-87, 2008.

LOPES, F.C.F.;AROEIRA, L.J.M.; RODRIGUEZ, N.M.; DERESZ, F.; SAMPAIO, I.B.M.; PACIULLO, D.S.C.; VITTORI, A. Efeito da suplementação e do intervalo de pastejo sobre a qualidade da forragem e consumo voluntário de vacas Holandês x Zebu em lactação em pastagem de capim-elefante. Arquivo Brasileiro de Medicina Veterinária e Zootecnia, v.56, p.355-362, 2004.

MAYES, R.W.; LAMB, C.S.; COLGROVE, P.M. The use of dosed and herbage n-alkanes as markers for the determination of herbage intake. Journal of Agriculture Science, v.107, p.161-170, 1986.

MILFORD, R.; MINSON, D.J. Intake of tropical pasture species. In: CONGRESSO INTERNACIONAL DE PASTAGENS, 9, 1965, São Paulo. Anais. São Paulo: Secretaria de Agricultura, 1966. p.815-822.

MORENZ, M.J.F.; SILVA, J.F.C. da; AROEIRA, L.J.M.; DERESZ, F.; VASQUEZ, H.M.; PACIULLO, D.S.C.; LOPES, F.C.F.; ELYAS, A.C.W.; DETMANN, E. Óxido de cromo e n-alcanos na estimativa do consumo de forragem de vacas em lactação, em condições de pastejo. Revista Brasileira de Zootecnia, v.35, p.1535-1542, 2006.

NATIONAL RESEARCH COUNCIL. Nutrient requirements of dairy cattle. 7.ed. Washington: National Research Council, 2001. 381 .

NEVES, C.M.N.; SILVA, M.L.N.; CURI, N.; MACEDO, R.L.G.; MOREIRA, F.M. de S.; D’ANDRÉA, A.F. Indicadores biológicos da qualidade do solo em sistema agrossilvipastoril no noroeste do Estado de Minas Gerais. Ciência e Agrotecnologia, v.33, p.105-112, 2009.

PACIULLO, D.S.C.; CAMPOS, N.R.; GOMIDE, C.A.M.; CASTRO, C.R.T. de; TAVELA, R.C.; ROSSIELLO, R.O.P. Crescimento de capim-braquiária influenciado pelo grau de sombreamento e pela estação do ano. Pesquisa Agropecuária Brasileira, v.43, p.917-923, 2008.

PACIULLO, D.S.C.; CARVALHO, C.A.B. de; AROEIRA, L.J.M.; MORENZ, M.J.F; LOPES, F.C.F.; ROSSIELLO, R.O.P. Morfofisiologia e valor nutritivo do capim-braquiária sob sombreamento natural e a sol pleno. Pesquisa Agropecuária Brasileira, v.42, p.573-579, 2007.

PAES LEME, T.M.S.; PIRES, M. de F.Á.; VERNEQUE, R. da S.; ALVIM, M.J.; AROEIRA, L.J.M. Comportamento de vacas mestiças Holandês x Zebu, em pastagem de Brachiaria decumbens em sistema silvipastoril. Ciência e Agrotecnologia, v.29, p.668-675, 2005.

ROZADOS-LORENZO, M.J.; GONZÁLEZ-HERNÁNDEZ, M.P.; SILVA-PANDO, F.J. Pasture production under different tree species and densities in an Atlantic silvopastoral system. Agroforestry Systems, v.70, p.53-62, 2007.

SAS INSTITUTE. SAS/STAT: user's guide. Version 8.1. Cary: SAS Institute, 2001. 943p.

SENANAYAKE, S.G.J.N. The effects of different light levels on the nutritive quality of four natural tropical grasses. Tropical Grasslands, v.29, p.111-1114, 1995.

SILVA, D.J.; QUEIROZ, A.C. de. Análise de alimentos: métodos químicos e biológicos. Viçosa: UFV, 2002. 235p.

SOARES, A.B.; SARTOR, L.R.; ADAMI, P.F.; VARELLA, A.C.; FONSECA, L.; MEZZALIRA, J.C. Influência da luminosidade no comportamento de onze espécies forrageiras perenes de verão. Revista Brasileira de Zootecnia, v.38, p.443-451, 2009.

SOUSA, L.F.; MAURÍCIO, R.M.; GONÇALVES, L.C.; SALIBA, E.O.S.; MOREIRA, G.R. Produtividade e valor nutritivo da Brachiaria brizantha cv. Marandu em um sistema silvipastoril. Arquivo Brasileiro de Medicina Veterinária e Zootecnia, v.59, p.1029-1037, 2007.

XAVIER, D.F.; CARVALHO, M.M.; ALVIM, M.J.; BOTREL, M.A. Melhoramento da fertilidade do solo em pastagem de Brachiaria decumbens associada com leguminosas arbóreas. Pasturas Tropicales, v.25, p.23-26, 2003.

Recebido em 7 de julho de 2009 e aprovado em 25 de setembro de 2009 